\title{
Smart system for monitoring ammonium nitrate storage warehouse
}

\author{
Maha Khalil Ibrahim¹, Nadia Mahmood Hussien², Saad Najim Alsaad ${ }^{3}$ \\ ${ }^{1}$ Mobile Communications and Computing Engineering Department, College of Engineering, University of Information \\ Technology and Communications, Baghdad, Iraq \\ ${ }^{2,3}$ Computer Science Department, College of Science, Mustansiriyah University, Baghdad, Iraq
}

\begin{tabular}{l} 
Article Info \\
\hline Article history: \\
Received Jan 16, 2021 \\
Revised May 29, 2021 \\
Accepted Jun 11, 2021 \\
\hline
\end{tabular}

\section{Keywords:}

Ammonium nitrate

Arduino

Ds18b20 sensor

Functional requirements

GPS

GSM

MQ sensors

UML

Use case diagram

\begin{abstract}
Ammonium nitrate (AN, NH4NO3) is one of the materials used in chemical industry and in agriculture. AN is not considered a fire risk but it is a strong oxidizing agent that can lead to fire and explosion, so, the ammonium nitrate must be stored under specific environmental conditions to avoid the occurrence of dangerous situations. In this paper, a smart monitoring system for Ammonium nitrate storage is developed. The system consists of threeparts: monitoring chemicals system part (MCS), warehouse monitoring part (WMP), and emergency part (EP). MCS includes several hardware components: Arduino microcontroller, Ds18b20 sensor, MQ sensors, system for mobile communication (GSM), global position system (GPS), buzzer, and LCD. Two types of alarms are designed, the first one is for the WMP that to receive the alarm when temperature is exceeds than a specific threshold in chemical warehouse. The second one is for EP. It represents the receiver part to receive the alarm with the location of the place that indicates to certain gases leakage that could cause a fire or explosion. Also, a buzzer is listening and display the sensor state on LCD. The system follows the objectoriented software engineering (OOSE) approach using unified modeling language (UML).
\end{abstract}

This is an open access article under the CC BY-SA license.

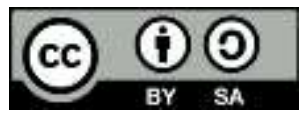

\section{Corresponding Author:}

Saad Najim Alsaad

Department of Computer Science

Mustansiriyah University

Mustansiriyah Road, Baghdad, Iraq

Email: dr.alsaadcs@uomustansiriyah.edu.iq

\section{INTRODUCTION}

Ammonium nitrate NH4NO3 (AN) is an industrially significant item employed far and wide, with a yearly worldwide utilization of in excess of 20 million tons [1]. It's an inorganic compound initially found in 1659. AN as a raw material has positive and negative impacts on the environment and human lives. In positive it has been utilized in agriculture and chemical industries. It has wide applications in the field of nitrogen fertilizers and has replaced urea in some cases as well as a clean energy source in the aerospace industry due to its natural friendly environment [2]. Also, AN is used as an alternative of dynamite utilized for rocks blasting in industries. As a negative part, AN is a powerful material and is considered as source of oxygen and its application is as an oxidizer in explosives and propellants [3], [4]. Its hazard exists throughout the storage, production and transportation when quickly heated, stroke, or detonated, which leads to a huge number of casualties with different types of loos [5]. The use of AN lead also to many consequences like horrible explosion causalities and environmental pollution, causing various disasters until the present day [2], [4], [6]. One of these explosions was on August 4, 2020, the explosion witnessed in the Lebanese 
capital, Beirut, which caused in the death of a large number of victims and dozens of wounded in addition to the economic losses that the city suffered, and it was not the first explosion caused by ammonium nitrate, as it was preceded by several explosions, the most famous are:

- On 21st September 2001, A terrible explosion of ammonium nitrate, occurred in Toulouse, in AZF factory which is a property of Grande Paroisse Company, TotalFinaElf Group, killing 30 people, .The main industrial chemicals in the factory were ammonium nitrate, ammonium nitrate-based fertilizers with another chemicals and chlorinated combinations [7].

- On July 30, 2009 a factory managed by El Dorado Chemical company blazed. No explosion occurred in $\mathrm{AN}$, however specialists on call arranged for the explosion by clearing to one mile, at that point in this manner needed to empty the majority inhabitants of the city when the cloud of gas began clearing across the city. More than 80,000 occupants were cleared altogether [8].

- On 17 April 2013 an enormous burst occured in West, Texas ,a small town in central Texas, within a short time after the work time on the disaster day, the fire source was in a room allocated for storing seed close to the ammonium nitrate (AN) storage [9].

- On August 12, 2015 On August 12, 2015, Tianjin Port, in the Tianjin Binhai New District (China), encountered explosion of approx. 800 tons of NH4NO3. The massive eruptions caused a large number of flames in the field and the presence of mushroom spray [10].

- On August 5, 2020, the capital of Lebanon, Beirut was shoked by an explosion that has killed at least 180 people and injured thousands (Bressan, 2020). The main cause of the explosion was the large amount (approximately 2750 Tons) of NH4NO3 at the site. The decomposition of huge amount of ammonium nitrate not only took the lives of hundreds of people but has also heavily pumped nitrites as well as $\mathrm{CO} 2$ \& $\mathrm{CO}$ into the environment [11].

In this paper a smart system has developed. It detects and warns of dangerous situations that may lead to heating of ammonium nitrate and exposing it to ignition. The aim of the system is to reduce human and economic losses by monitoring and sensing risks before they occur. The developed system is based on Arduino and GSM (global system for mobile communication). Arduino can be defined as an open source microcontroller platform founded on a simple input/output ( $\mathrm{I} / \mathrm{O}$ ) board in which the processing is executed by a development environment [12]. GSM is a module which used to transmit data, voice, and SMS (short message service) [13]. We can define GPS as one of the beneficial technology that is one of the most effective general-purpose navigation tool ever established and improved to date. The GPS receiver is a device that using to get the location information and it's always attached with an antenna [14].The system is developed based on an object oriented programming (OOP) approach rather than procedural approach. In a nutshell, object OOP deals with the primary main parts or building blocks of the problem, while focusing on required steps to produce the desired outcomes is a Procedural programming [15].

\section{RELATED WORK}

The design and implementation of Arduino based systems has been applied in several applications. A brief literature review is given hereafter: A home fire alarm system based Arduino and GSM Module has been designed by Mahzan et al. The hardware requirements used in the system are (Arduino Uno microcontroller, LM35 temperature sensor, LCD, GSM). When the temperature is reached to $40^{\circ} \mathrm{C}$ or more, the system sends a short alarm message to the home owner mobile via GSM network, also an alert notification on LCD will display [16]. Khaing et al. [17] developed an automatic temperature control system for controlling of temperature in the smart home and modern gadgets. The hardware requirements needed in the system are (Arduino Uno microcontroller, LM35 temperature sensor, LCD). Temperature is displayed on LCD display to control the temperature in the room. The detection of gas leakage has been presented by Ghosh, P. and P.K. Dhar by designing a system that has the ability to discover gas leakage in addition to discover explosion and fire too. The flame sensor discovered the fire and makes high output.

Arduino switched on the buzzer and solenoid valve after getting the high output. The LCD showed the fire alert message and the GSM sent a message to the owner .The virtual terminal showed the SMS sending by GSM [18]. The level of humidity monitoring was described by Susa et al. by proposing a system for automatic room humidifier and dehumidifier to ensure the comfortably of the user, by using Arduino Uno microcontroller, humidity sensor, Rely, and LCD, when the sensor reaches to certain value of humidity, the humidifier is activating automatically. LCD used to display the value of sensor [19]. Another wireless home safety system presented by Muheden, K., E. Erdem, and S. Vançin. They designed a simple hardware circuit and used notification as a technique of notifying users linked to system. The sensors provide the Arduino device with received fire, temperature, gas, and humidity signals. The Arduino identifies the collected information with control levels overtake a predefined threshold and communicate with WiFi network for the 
notification alarm message sending to the mobile users to pre-screen the capability of a fire event [20]. Varma, Prabhakar, and Jayavel proposed a system that uses an MQ-2 sensor for gases detecting, and the ability to diagnose the leakages of hurtful gases and alerting through heard alarms with the help of IoT, alarming the relevant authority about the situation before any accident happens through a message utilizing GSM module, individual call and sending e-mail contains the details of the area throughout an Arduino Ethernet Shield [21]. Other efforts have been made by Srivastava, that examines the existence of poisonous gases in serious regions and their impacts on miners. A wireless sensor network used by a real time monitoring system, which combines multi sensors, is improved. The surrounding environmental parameters for example temperature, humidity, and different toxic gases has been screened by the system. An early warning is also provided by the system to help all miners exist inside the mine for saving lives prior to any accident occurs. The Zigbee technology is used by the system for establishing wireless sensor network. It is a wireless networking standard IEEE 802.15.4, which is appropriate for operation in harsh environment [22]. Designing of explosive detector device is suggested by Rahmawan that can diagnose the existence of explosives through the comparison of the value of the magnetic field so that an object will be shown to be an explosive or not to present more information with the Juana airport area as an alternative of conventional explosive detector equipment. A magnetometer sensor is used by the design that has the ability to calculate the magnitude of the magnetic field in the explosives and it is able to send analog inputs as voltage values to the Arduino showed with LCD media and the buzzer makes sound, so that the category of explosives can be diagnosed [23]. A hazardous gases detection system was presented by [24] through designing a system for hazardous gases detection. Finally, an ammonia (NH3) sensor is developed with Arduino using the PANi solution. The sensor is operated with room temperature and gives a response less than $100 \mathrm{~s}$ and can detect the harmful gas [25]. The proposed system is composed of LCD Monitor, GSM, Arduino, three different sensors and three different color lamps. The Arduino acts as controller to indicate the level of gas by one of the color lamps displayed on LCD monitor. The notification is represented as GSM message sent by GSM module. The system has the ability to detect LPG with 50 inches and detect both Hydrogen and methane gases with 30 inches distance

\section{REQUIREMENTS}

The functions or the services of the proposed system are presented as high-level abstract statements through the following classification.

\subsection{Functional requirements}

a) The higher of temperature of warehouse is automatically detected.

b) The leakage of gases is automatically detected.

c) The fire in warehouse automatically detected.

d) The location of warehouse automatically determined.

e) Provide facilities for rapid alarm and immediate response.

- The system should send an alarm message SMS to warehouse monitoring part (WMP) and emergency part (EP)

- The system should send the location of warehouse which exposed to problem.

- The system should raise an alarm to alert about any unwanted state.

f) Display the state of the sensors on LCD and update every 5 second automatically.

\subsection{Nonfunctional requirement}

Three types of nonfunctional requirements are considered: quality, platform and methodology requirement:

a) Quality Requirements

- Response time: is a basic principles of quality requirements. The system should be designed in a rapid response time to any situation.

- Reliability: The system should be give same results continuously in the same condition.

- Availability: The system should be able to be used in all the time.

- Allowances for maintainability and enhancement: - The system has the flexibility to add hardware or software for improvement.

b) Platform Requirements

This type of requirement includes the environment and technology of the system:

- Computing platform: the system works on windows 10 operating system 64 bit with 4GB RAM/1.80GH processor, Arduino Uno microcontroller R3 , MQ5 sensor, MQ9 sensor, Ds18b20 
sensor, GSM,GPS neo 6m, LCD, Bread board, Resistance, Jumper wires, Buzzer, PC, power supply and Cable.

- Technology used: The system uses Arduino C language also in addition to many another tools and libraries includes GSM, LiquidCrystal, TinyGPS++, SoftwareSerial, SPI, OneWire-master, DallasTemperature libraries, (StarUML application).

c) Methodology Requirements

The system designs and implementations according to an object oriented methodology using unified modeling language (UML).

\section{USE CASE MODELING}

A UML use case diagram is a visual tool which gives a simple way for understanding among developer's system's, end users and domain experts. The use case diagram consists of use case/cases and actors/actors. Each actor implements one or more use cases. Figure 1 depicts the general system use case model. It consists of three actors and six basic use cases with (association, generalization, and inclusion) relations.

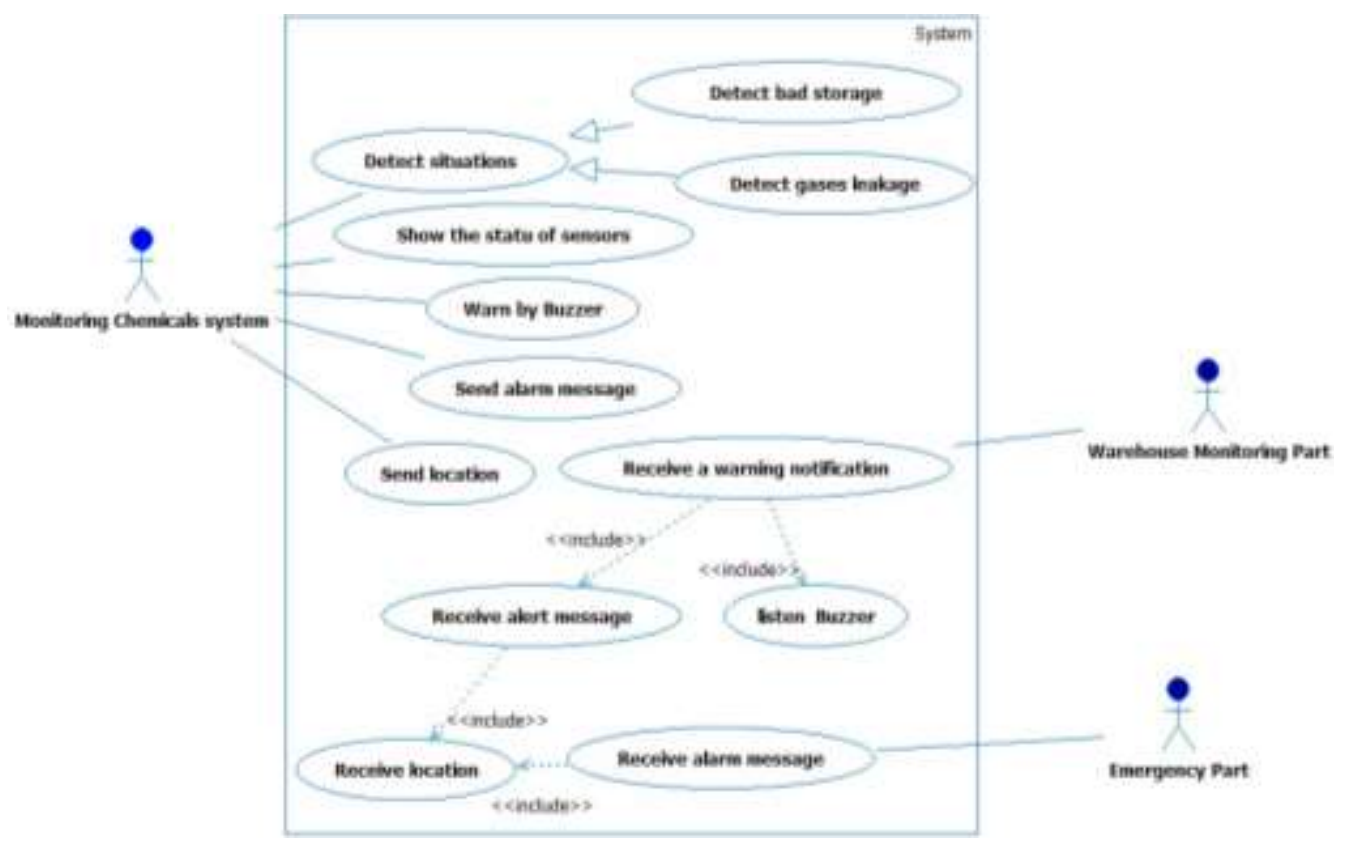

Figure 1. Use case diagram of the system

\section{CLASS DIAGRAM}

The system is modeled by class diagram which is a static structure diagram. It includes all attributes and operations that are needed to investigate the system. Figure 2 illustrates the classes and their relations (association and generalization).

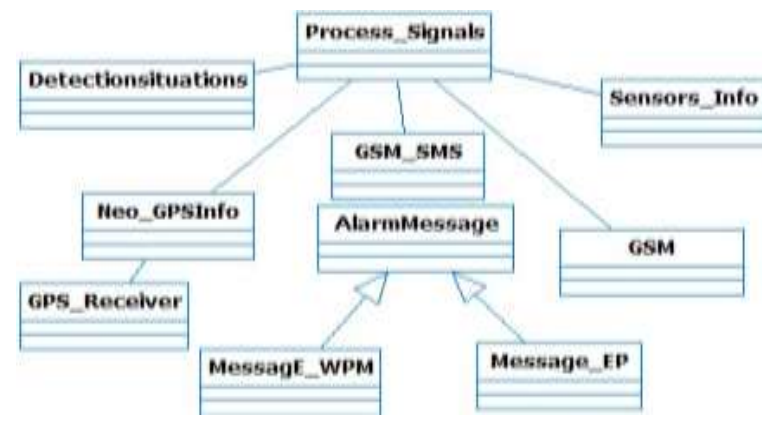

Figure 2. Class diagram of the system 


\section{PROPOSED SYSTEM}

The system consists of three-parts: monitoring chemicals system (MCS) part, warehouse monitoring part (WMP), and emergency part (EP). The design of MCS part is controlled by ATmega328 which is connected to the many components: DS20B18 temperature sensor, MQ5 sensor, MQ9 sensor, GPS, GSM, LCD, and buzzer. Figure 3 represents the block diagram of the MCS. It includes all sensors and GPS as an input modules microcontroller as a processing unit while GSM, LCD and buzzer as an output unit.

The temperature sensor continuously measures the temperature for the warehouse. If the temperature is exceeding to a predetermined value, an SMS alarm message will be sent to the second part (WMP) by the GSM module to indicate bad storage for chemicals and M9 are used to monitor the leakage of gases in the warehouse. MQ5 sensor is sensitive for natural gas, LPG, coal gas, methane, Ethanol, and other gases. MQ9 sensor is sensitive to Carbon Monoxide, flammable gasses, and other gases. If any leakage for gases is detected, the SMS alert message will be sent to the EP part by the GSM module.

The values of temperature and the notification of gas sensors are displayed on the LCD. Also, SMS alarm contains the location of the warehouse in Google application in form of latitude and longitude. Figure 4 depicts the hardware components of MCS part. The microcontroller is the heart of this part. It does control on all the components work. Arduino $\mathrm{C}$ language is used for programming MCS part.

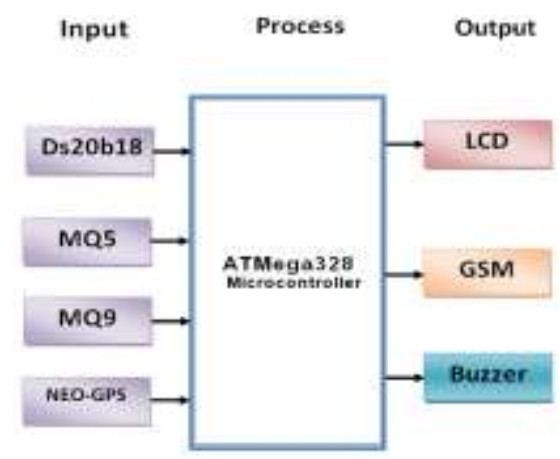

Figure 3. Block diagram of MCS

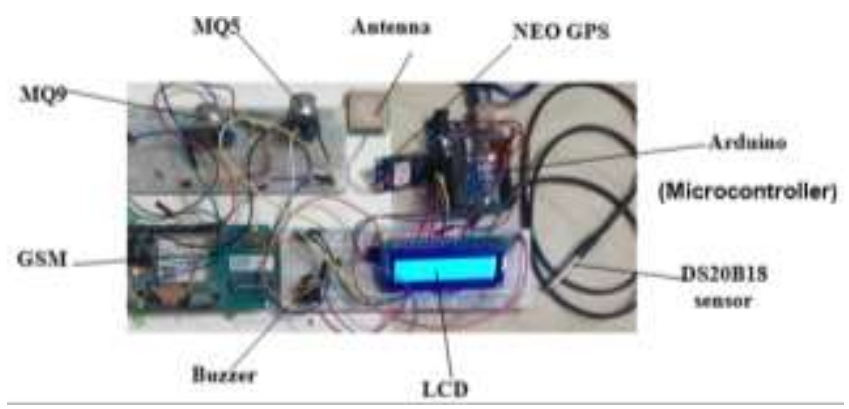

Figure 4. Hardware components of MCS part

\section{RESULTS AND DISCUSSION}

This section describes the results performed by the three parts of the whole system and their respective experiments as well as the overall system experiments. The system designed to reduce the risk of ammonium nitrate. The system in general monitors the storage status of ammonium nitrate. There are three status types:

- Status 1: Early warning begins if ammonium nitrate is poorly stored in the warehouse and the temperature exceeded the permissible limit of $55^{\circ} \mathrm{C}$ which represent the threshold that used mostly in fire detecting fire system. In this case, an alarm is initiated by triggering the buzzer, and sending SMS message to WMP part.

- Status 2: Critical alarm starts in case of leakage a gases that could lead to fire or explosion. In this case, an SMS message will be sent to (EP) part. Figure 5(a) and (b) represents status 1 and status 2 respectively.

- Status 3: The final status is when everything is normal. No alarm is initiated. Figure 6(a)-(c) illustrates the three cases on the LCD. 


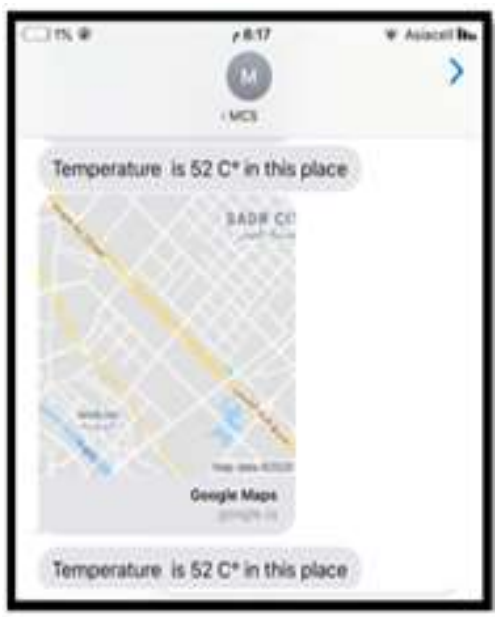

(a)

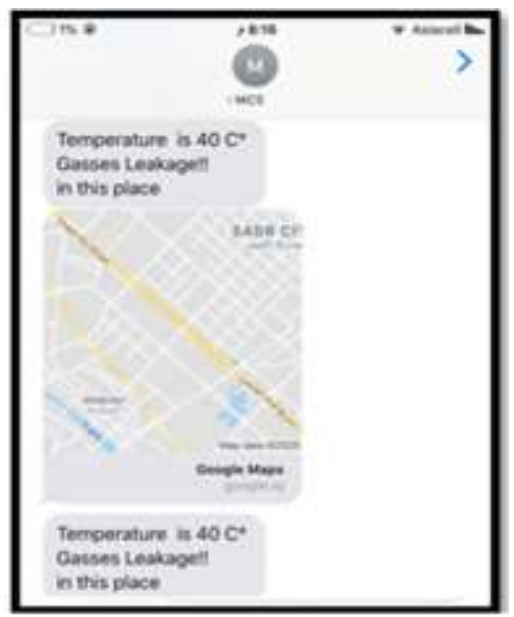

(b)

Figure 5. Status 1 and status 2 respectively; (a) SMS alarm when bad storage occurred and (b) SMS alarm when gases leakage occurred

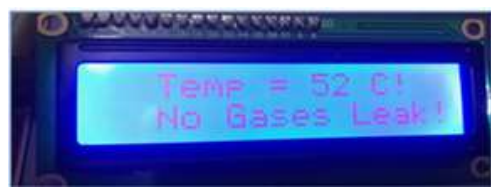

(a)

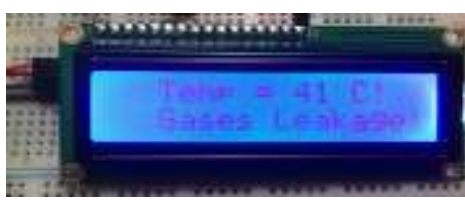

(b)

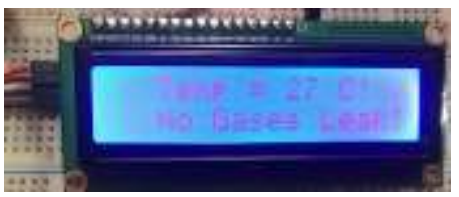

(c)

Figure 6. The final status; (a) Status 1, (b) Status 2, and (c) Status 3

\section{CONCLUSION}

Based on the results, the system can effectively identify and monitor the storage of ammonium nitrate (AN) warehouse. In this paper a smart alarm monitoring system for ammonium nitrate has been designed and implemented. It's a real-time system that aimed to reduce the victims and economic losses. It gives the correct location of ammonium nitrate warehouse with high accuracy and inform on the type of problem that occurs. It developed based on object-oriented approach employed the intelligent sensors. The system designed using a simple module with low cost and ease of use. It should be noted that ammonium nitrate undergoes decomposition at higher temperatures $\left(\geq 170^{\circ} \mathrm{C}\right)$. But in this research, the DS18b20 sensor has been used with detection capacity ranging from $-55^{\circ} \mathrm{C}$ to $125^{\circ} \mathrm{C}$ because the system aims to detect the problem earlier than the time it occurs. It is recommonded to using a humidity sensor to test the humidity value of stored AN at particular temperature. Also, adding new sensors such as MQ 137 Ammonia gas sensor and calibrated nitric oxide (NO) gas sensor will be helped to increase systems functionality.

\section{ACKNOWLEDGEMENTS}

We are grateful for the support received from the department of Computer Science/College of Science/Mustansiriyah University/Baghdad/Iraq and department of Mobile Communications and Computing Engineering/College of Engineering/University of Information Technology and Communications /Baghdad/Iraq for this research.

\section{REFERENCES}

[1] X. Baraza, A. Pey, and J. Giménez, "The self-sustaining decomposition of ammonium nitrate fertiliser: Case study, Escombreras valley, Spain," in Journal of Hazardous Materials, vol. 387, no. 121674, 2020, doi: 10.1016/j.jhazmat.2019.121674.

[2] V. Babrauskas, "Explosions of ammonium nitrate fertilizer in storage or transportation are preventable accidents," in Journal of Hazardous Materials, vol. 304, pp. 134-149, 2016, doi: 10.1016/j.jhazmat.2015.10.040. 
[3] S. Chaturvedi and P. N. Dave, "Review on Thermal Decomposition of Ammonium Nitrate," in Journal of Energetic Materials, vol. 31, no. 1, pp. 1-26, 2013, doi: 10.1080/07370652.2011.573523.

[4] H.-Q. Cao, L. Jiang, Q.-L. Duan, D. Zhang, H.-D. Chen, and J-H Sun, "An experimental and theoretical study of optimized selection and model reconstruction for ammonium nitrate pyrolysis," in Journal of Hazardous Materials, vol. 364, pp. 539-547, 2019, doi: 10.1016/j.jhazmat.2018.10.048.

[5] Z. Han, "Thermal Stability Studies of Ammonium Nitrate," Doctoral dissertation, Chemical Engineering, Texas A \& M University, USA, 2016.

[6] Y. Izato, K. Shiota, and A. Miyake, "Condensed-phase pyrolysis mechanism of ammonium nitrate based on detailed kinetic model," in Journal of Analytical and Applied Pyrolysis, vol. 143, no. 104671, 2019, doi: 10.1016/j.jaap.2019.104671.

[7] N. Dechy, T. Bourdeaux, N. Ayrault, M.-A. Kordek, and J.-C. Le Coze, "First lessons of the Toulouse ammonium nitrate disaster, 21st September 2001, AZF plant, France," in Journal of Hazardous Materials, vol. 111, no. 1-3, pp. 131-138, 2004, doi: 10.1016/j.jhazmat.2004.02.039.

[8] W. Pittman, Z. Han, B. Harding, C. Rosas, J. Jiang, A. Pineda, and M. S. Mannan, "Lessons to be learned from an analysis of ammonium nitrate disasters in the last 100 years," in Journal of Hazardous Materials, vol. 280, pp. 472-477, 2014, doi: 10.1016/j.jhazmat.2014.08.037.

[9] T. R. Merinar and S. Miles, "9 volunteer fire fighters and 1 off-duty career fire captain killed by an ammonium nitrate explosion at a fertilizer plant fire-Texas," A summary of a NIOSH fire fighter fatality investigation, F2013-11, 2014.

[10] B. Zhao, "Facts and lessons related to the explosion accident in Tianjin Port, China," Nat Hazards, vol. 84, no. 1, pp. 707-713, 2016, doi: 10.1007/s11069-016-2403-0.

[11] S. Ur Rehman, et al., "Ammonium nitrate is a risk for environment: a case study of Beirut (Lebanon) chemical explosion and the effects on environment," in Ecotoxicology and environmental safety, vol. 210, no. 111834, 2021, doi: 10.1016/j.ecoenv.2020.111834.

[12] M. Banzi and M. Shiloh, "Getting started with Arduino: the open source electronics prototyping platform," Maker Media, Inc, 2014.

[13] S. Akwu, U. I. Bature, K. I. Jahun, M. A. Baba, and A. Y. Nasir, “Automatic plant Irrigation Control System Using Arduino and GSM Module," in International Journal of Engineering and Manufacturing, vol. 10, no. 3, pp. 12-26, 2020, doi: 10.5815/ijem.2020.03.02.

[14] W. Joanne, S. Taking, N. Isa, and K. Chao, "Indoor navigation and localisation application system," $20163 \mathrm{rd}$ International Conference on Electronic Design (ICED), 2016, pp. 327-331, doi: 10.1109/ICED.2016.7804661.

[15] C. Oliveira, "The importance of learning computer programming for engineers," in Proceedings-International Conference on Industrial Engineering and Operations Management, Kuala Lumpur, Malaysia, 2016, pp. 2311-2314.

[16] N. N. Mahzan, N. I. M. Enzai, N. M. Zin, and K. S. S. K. M. Noh, "Design of an Arduino-based home fire alarm system with GSM module," in Journal of Physics: Conference Series, vol. 1019, no. 012079, 2018, doi: 10.1088/1742-6596/1019/1/012079.

[17] K. K. Khaing, K. S. Raju, G. R. Sinha, and W. Y. Swe, "Automatic Temperature Control System Using Arduino," in Proceedings of the Third International Conference on Computational Intelligence and Informatics, vol. 1090, 2020, doi: 10.1007/978-981-15-1480-7_18.

[18] P. Ghosh and P. K. Dhar, "GSM Based Low-cost Gas Leakage, Explosion and Fire Alert System with Advanced Security," 2019 International Conference on Electrical, Computer and Communication Engineering (ECCE), 2019, pp. 1-5, doi: 10.1109/ECACE.2019.8679411.

[19] J. A. B. Susa, M. A. F. Malbog, J. N. Mindoro, C. D. Casuat, and A. S. Alon, "Automatic Room Humidifier and Dehumidifier Controller using Arduino Uno," in International Journal of Advanced Trends in Computer Science and Engineering, vol. 9, no. 2, pp. 2208-2212, 2020, doi: 10.30534/ijatcse/2020/198922020.

[20] K. Muheden, E. Erdem, and S. Vançin, "Design and implementation of the mobile fire alarm system using wireless sensor networks," 2016 IEEE 17th International Symposium on Computational Intelligence and Informatics (CINTI), 2016, pp. 000243-000246, doi: 10.1109/CINTI.2016.7846411.

[21] A. Varma, Prabhakar S., and K. Jayavel, "Gas Leakage Detection and Smart Alerting and prediction using IoT," 2017 2nd International Conference on Computing and Communications Technologies (ICCCT), 2017, pp. 327-333, doi: 10.1109/ICCCT2.2017.7972304.

[22] S. K. Srivastava, "Real time monitoring system for mine safety using wireless sensor network (multi-gas detector)," Master Thesis, Department of Mining Engineering, National Institute Of Technology, Rourkela, India, 2015.

[23] Atmiasari and G. F. Rahmawan, "Explosive detector design to know the existence of explosive materials by comparing the large value of mednet magnet using arduino in Juanda airport area," in Journal of Applied Electrical, Science, \& Technology, vol. 2, no. 1, pp. 21-24, 2020, doi: 10.36456/best.vol2.no1.2582.

[24] M. Jualayba, K. Regio, H. Quiozon, and A. Destreza, "Hazardous Gas Detection and Notification System," 2018 IEEE 10th International Conference on Humanoid, Nanotechnology, Information Technology, Communication and Control, Environment and Management (HNICEM), 2018, pp. 1-4, doi: 10.1109/HNICEM.2018.8666358.

[25] S. M. Alure, R. V. Tonpe, A. D. Jadhav, S. T. Sambare, and J. D. Pagare, "Drainage Toxic Gas Detection System Using IoT,” in ICT Systems and Sustainability, pp. 161-167, 2020, doi: 10.1007/978-981-15-0936-0_15. 